\title{
Engaging Pre-Service and In-Service Teachers in Online Mathematics Teaching and Learning: Problems and Possibilities
}

\author{
Roland G. Pourdavood and Xuan Song \\ Cleveland State University, Cleveland, Ohio, USA \\ https://orcid.org/0000-0003-2777-7867 \\ https://orcid.org/0000-0003-4003-4195
}

\begin{abstract}
Many pre-service and in-service mathematics teachers have reflected vulnerabilities and unpreparedness for online teaching during the period of the COVID-19 pandemic. They searched for supports and resources to enhance their knowledge, skills, and dispositions relative to online teaching and learning. However, there is no clear path towards reaching these goals. This qualitative and interpretive research focuses on 48 pre-service and in-service teachers' online teaching and learning experiences; while they were engaged in a semester-long mathematicsmethod course. The findings of this study suggest that factors, like interactions, communication, and peer support impact the pre-service and the in-service mathematics teachers' beliefs and practices toward online teaching and learning. The findings also suggest that social and cultural factors, such as knowing and understanding students' cultural background, access and equity in mathematics education, learners' social and emotional development, and parents' involvement influence mathematics teachers' practices regarding online teaching and learning. The findings indicate that the transformation from in-person to online learning requires the enhancement of pre-service and in-service mathematics teachers' online preparations, particularly in the areas of technology, pedagogy, communication skills, and classroom management.
\end{abstract}

Keywords: mathematics online teaching; teaching and learning; preservice and in-service teachers; teachers' collaboration

\section{Introduction}

The COVID-19 pandemic has situated school education in an unprecedented level of online teaching. However, many teachers experience challenges when they are trying to implement online teaching during this specific time, including planning, instruction, communication, and assessment challenges. This phenomenon is particularly salient in the subject of mathematics in K-12 schools. A considerable 
number of mathematics teachers' (pre-service and in-service) search for additional resources to advance their knowledge, skills, and dispositions relative to online teaching and learning demands. In a qualitative study gathering feedback from elementary Indonesian teachers on how the COVID-19 pandemic has influenced their teaching, it was reported that $73.9 \%$ of teachers considered online learning to be ineffective; and $80 \%$ of those teachers were dissatisfied in general (Fauzi \& Khusuma, 2020). The most significant concerns reported by these teachers include limited availability of resources, network and internet issues, limited time to plan, difficulty with the implementation of lessons and the evaluation of students' performance, and difficulty collaborating with parents (Fauzi \& Khusuma, 2020).

Although this study took place in Indonesia, when looking at the technological tools used by teachers (e.g., Zoom, Google Classroom, YouTube), they are like the tools used in the United States and around the world. It can be assumed that the struggles teachers and students face are very similar around the world. Adedoyin \& Soykan (2020) detail several challenges and opportunities of online learning, as they relate to the pandemic. The challenges reported were pandemic-related anxiety affecting students' performance, socio-economic and racial differences affecting students' ability to access resources, the lack of digital competence to effectively use online programs, intrusions from families and pets during instructional time, difficulty assessing and supervising students, heavier workloads, the need for in-person experiences for certain content areas, and the general ability of instructors to adapt to the new format quickly enough, in order to effectively deliver instruction (Adedoyin \& Soykan, 2020).

Another concern regarding online teaching and learning is the comparison and the adaptation between the traditional onsite classroom model and the online model from many students' perspectives. In a study conducted in Pakistan, undergraduate and graduate students' experiences and opinions related to online learning were recorded. The study found that many students did not have access to good internet connection (51.6\%); they did not think they were getting the same education as they would in-person $(67.5 \%)$; they thought that their courses were not effectively taught (50.8\%); and they thought that it was difficult to complete projects and assignments digitally $(42.9 \%)$.

A number of the students surveyed stated that in-person learning is more motivating; and face-to-face contact with the instructors is necessary $(78.6 \%)$, even though most students felt qualified to use a computer $(71.4 \%)$ and were comfortable communicating electronically (61.1\%) (Adnan \& Anwar, 2020). Many teachers seem to agree with students that online teaching and learning is ineffective and challenging; but this does not change the reality that this is the current state of the world; and adaptations need to be made for the best interests of all the students.

Studies also show that many pre-service mathematics teachers face technological and pedagogical challenges, while engaging mathematics teaching online. To help these teachers to be well prepared in their future mathematics classes, a few solutions have been proposed by some mathematics educators, including the 
curriculum-wide integration of technology (Kay, 2006), content-specific technology integration (Koehler and Mishra, 2009), and collaboration with mentor teachers on the integrative use of technology throughout their teaching and learning processes (Bullock, 2004). Dorner \& Kumar (2016) further found that oneon-one mentoring and group mentoring are the most effective approaches to assist pre-service mathematics teachers to use technologies in their lesson planning and classroom teaching. Exploring the above issues and searching for possible pedagogies regarding online mathematics teaching and learning may benefit pre-service and in-service mathematics teachers, who are in serious need of assistance to enhance their knowledge, skills, and dispositions.

\section{Review of the Literature}

The topic of effective online mathematics teaching has been a hot topic among many mathematics educators since the onset of the COVID-19 pandemic. In the following section, we discuss the studies about the "why", "what", and "how" of online mathematics teaching, learning, and assessment.

\section{Why Can Mathematics Be Taught Online?}

Educators have a long history of discussing why mathematics can, or should be, taught online. Online mathematics teaching and learning originated in a context of the educational shift from traditional onsite learning to the method of utilizing internet services for teaching and learning. Over the past few years, as the internet has been integrated into a multifaceted communication platform, including instruction, interaction, and evaluation, it has provided a stimulating learning environment for engaging learners in meaningful learning (Macdonald et al., 2001). The number of online courses has increased rapidly; and this has become a significant constituent of education worldwide. The web-based pedagogy brings about not only a shift in the mode of educational delivery, but also in the teaching approaches.

Czerniewicz (2001) emphasizes that network education is not only characterized as a paradigm shift in its promise of anytime and anywhere, but the paradigm shifts have also occurred in the interaction between the pedagogy and the technology in the instructional design of online courses (Engelbrecht \& Harding, 2005). This idea was also supported by Macdonald et al. (2001), when they wrote "Some instructors may need to adopt a more constructivist approach to their teaching. This would require a role shift from authoritative teacher to facilitator." (Engelbrecht \& Harding, 2005, p. 236). Indeed, the interactive approaches and instant feedback offered by well-designed online courses win over the traditional chalk-featured approach. That might be the claim by Quoting Bookbinder (2000) that "enhancing the mathematics curriculum with web-based technology takes time and effort; but the effort is well worth it." (Engelbrecht \& Harding, 2005, p. 238).

The booming of online mathematics teaching and learning is also due to the advancement of distance learning. The development of distance learning has increased exponentially over the past few years across the globe. A quick search of this topic results in hundreds of academic journal articles. Educators have 
developed a variety of technologies and platforms to promote distance learning. One salient approach of distance education is to use Information and Communication Technologies (ICT) to promote online sharing, discussions, and collaboration (Gueudet et al., 2012). By interacting with such networks, teachers can be involved in their own professional development. In addition, online exchanges, and collaborations by teachers in their daily educational practices inform their instruction; and it enhances students' learning. Through the model of ICT, "teachers can be involved in the activities of inquiry and exploration, as well as collaboration, in addition to the sharing, of mathematical (teaching) problems and projects, of resources and documents and the development of their teaching experiences." (Gueudet et al., 2012, p. 718). ICT provides a dynamic platform for mathematics teachers, educators, researchers, and curriculum developers to come together and engage in educational activities.

\section{What Is Online Mathematics Teaching?}

The definition of online mathematics teaching may not have a compatible consensus, but it purports to derive from a general online teaching category; and it has its distinctive features. Rapanta et al. (2020) have defined online learning as the following:

"A type of teaching and learning situation in which (1) the learner is at a distance from the tutor/instructor; (2) the learner uses some form of technology to access the learning materials; (3) the learner uses technology to interact with the tutor/instructor and with other learners; and (4) some kind of support is provided to learners." (p. 925).

Herzig (2020) explains online teaching and learning as one specific means of distance learning, which utilizes many tools, such as: Zoom, Skype, Dropbox, Blackboard, Canvas, Slack, VoiceThread, email, online chats, video chats, MS teams, Google docs, and many others, in order to conduct subject teaching and learning. As the application-oriented nature of the mathematics courses, there is no consensus on the definition of online mathematics teaching. Akdemir (2010) interprets this term from three categories, namely course materials, teaching process, and course assignments, which are combined in one theme termed as online-course teaching.

Based on this explanation, online mathematics teaching and learning utilizes virtual materials, such as lectures, demonstrations, videos, games etc., rather than using actual tools like pens, rulers, calculators to cognate concepts. In online situations, the teaching and learning process can take place 24 hours per day, all year long, in which the student organizes his or her training process; while the teacher guides that action by allowing unlimited access to the network resources.

\section{How Do We Teach Mathematics Online?}

In the field of online mathematics teaching, some models may provide teachers with insights and the necessary tools to engage their students. Moreno-Guerrero (2020) summarized certain models, such as the MCIEC model (motivation, context, interactivity, evaluation, and connectivity). The MCIEC model allows the students to increase their ability to attempt to understand the mathematical content, as well as to increase interest, motivation, and adaptation to the context. 
Another model is the Working Memory Capacity (WMC) method. This method leads to an improvement in students' abilities to acquire various mathematical concepts, which then improve students' academic performance. The next two models are even more influential. The Mentored Innovation Model (MIM) is one of them. The MIM is an online collaborative mentoring approach focusing on the authentic, problem-based classroom application of technology integration. The MIM combines multiple strategies for scaffolding the integration of pre-service and in-service teachers' technology in the teaching and learning process (Dorner \& Kumar, 2016).

The MIM model was the result of the European Pedagogical Information and Communications Technology Licensed (EPICT) project and the Calibrate project, involving schools, educational organizations, and the ministries of education from eight European countries. The MIM consists of three phases that aim to support the integration of pre-service and in-service teachers' technology into their teaching practices.

In the first phase of the model, the pre-service teachers identified pedagogical and methodological problems in the technology integration in collaboration with teacher educators, a subject-specific mentor, and educational researchers. Once these pre-service teachers had identified a problem that involved technology integration, they created project plans for materials, resources, or lesson plans, and a joint research agenda for the targeted content areas, in order to guide the team of mentors and peers. Throughout this second phase, the pre-service teachers were provided with sustained and ongoing professional support from their mentors, as well as a collaborative opportunity to engage hands-on with the complex technical, and pedagogical issues of applying technology to specific content areas (Dorner \& Kumar, 2016).

In the third phase, existing learning objects, activities, lesson plans etc. were identified and further developed in collaboration with peers through scratching input from their peers and teacher educators. Throughout the three phases, Computer-Supported Collaborative Learning (CSCL) environments were implemented for the online collaborative mentoring processes.

Dynabook development is another framework offering mathematics teachers a useful tool for engaging students with online learning. Dynabook is an interactive web-based tool that assists teachers to more effectively teach mathematics strategies. Dynabook was developed at San Diego State University through a collaboration between the Stanford Research Institute (SRI), Center for Applied Special Technology (CAST), and Universal Design Learning (UDL) developers and graduate students. The framework has become a unique combination of expertise in mathematics, mathematics education, special education, teacher training, technology-supported mathematics instruction, UDL pedagogy, and evaluation (Courey et al., 2012). Dynabook initiated, as an interactive mathematics platform for teacher candidates to teach general and special education subjects, to exchange mathematics pedagogy, and to utilize technology integration. 
Dynabook is based on Alan Kay's (1972) Dynamic Computational theory that "the dynamic, interactive capabilities of computational media as opening up new ways to playfully engage with powerful ideas, through activities like programming, interacting with visualizations, exploring mathematical models, and engaging with simulations." (Courey et al. 2012, p. 1). The salient feature of Dynabook is that it incorporates interactive problems, video, and aspects of UDL, in order to increase access for teacher candidates to better understand proportionality, and how to teach it during their instructional practices. In this sense, Dynabook allows teachers access to, and engagement with, challenging mathematics.

There are certain sporadic studies beginning to address the issues of online teaching and learning within the context of the COVID-19 pandemic. Rapanta et al. (2020) argued that online learning ought to be based on the materials (e.g., readings, videos, exercises), rather than on the actual interactions (e.g., discussions, presentations). They stated that students should be more autonomous in their own learning, be very alert to what they need, and be sure to keep asking and listening, while the extra communication channels remain open. Teaching and learning in an online format should be a student-centered approach, where their ideas and feedback are valued. Students should be assigned good tasks that are doable and make sense to them (i.e., expectations that are clear, and students understand the "why").

Regarding what makes online teaching and learning successful, students and teachers need to have access to technology and a good internet connection. More than this, however, students and teachers need to have autonomy (i.e., the ability to set goals, manage time, avoid distractions) during learning, as well as outside the "virtual classroom" (Rapanta et al. 2020). Therefore, this study suggests that activities should be based on a mixture of design approaches (i.e., online, offline) and be related to authentic contexts, in order to increase engagement and to be accessible.

Similarly, assessment should be strongly tied to the desired learning outcome, as an opportunity for students to demonstrate their mastery. However, teaching and learning online have made the assessment process increasingly difficult for many teachers. How does a teacher make sure that she is providing her students with the best educational experience possible, and that she is accurately assessing them virtually? According to Rapanta et al. (2020), a continuous assessment model must be adopted, such as using several smaller, formative assessments, rather than one large summative one.

These authors encourage the expectation of self-regulation (students' efforts to manage their learning processes to achieve their goals), and even to use these in their assessment by way of self-reflection assignments, or by using portfolios. Another way to promote self-regulation is to utilize self-paced, asynchronous assignments with an established timeline to foster the responsibility of their own (Rapanta et al. 2020). These authors suggest that the method the teacher chooses for assessing students and gathering data depends on the level of comfort the 
teacher has with online learning, in addition to what would be developmentally appropriate for his/her students.

\section{The Context of the Study}

This study is conducted in a State-supported university located in a large metropolitan area of Midwestern America. All the participants are enrolled in a semester-long three-credit hours course, called Mathematics Instruction Methods in Grades $P-5$. The course has a dual-numbered section that includes both graduate and undergraduate students. There were 48 students registered in these two online classrooms in the fall semester of 2020 ( 40 females and 8 males). Thirty-five students were undergraduate pre-service teachers and 13 were graduate inservice teachers. Among the 48 pre-service and in-service teachers, sixteen were special education majors, with an emphasis on a mild/moderate intervention specialty. The other 32 participants were in the early-childhood program. Due to the COVID-19 pandemic, the course is offered remotely via zoom meetings.

\section{The Methodology}

This research focuses on 48 pre-service and in-service mathematics teachers' online teaching and learning experiences, while they were engaging in a semesterlong mathematics method course. The purpose of the study was to understand and interpret the participating mathematics teachers' lived experiences regarding online teaching and learning. In this sense, the study chooses socio-cultural theory, as the theoretical lens; and it uses the Interpretive Phenomenological Approach (IPA), as the research method to search for meanings.

Two research questions were designed. First, what kind of teaching supports the participating mathematics teachers' need for online teaching? Second, how do we help the pre-service and the in-service mathematics teachers to fully embrace online teaching and learning? The data cover a wide range of sources, including the participants' reflections, problem-solving activities, lesson plans, peer critiques, group discussions, assessments, in addition to the researchers' filed notes.

\section{The Theoretical Framework}

The study chose the socio-cultural theory as its theoretical framework (Cobb, 1994; Cobb \& Yackel, 1996; Radford et al., 2018; Roth \& Walshaw, 2015; Rowlands, 2010; Vygotsky, 1978). Creswell (2013) argued that knowledge is a product of humans; and it is socially constructed. The basic idea of the socio-cultural theory is that all learning and knowledge are inherently constructed within the social and cultural milieu. Green and Piel (2010) view the construction of knowledge as a complete cultural entity; and it is taking place through a negotiation of meaningful dialogue with the participants in its various socio-cultural contexts.

Engelbrecht and Harding (2005) argue that the socio-cultural theory is the process of knowledge acquisition; and it is constrained by what one already knows and by cultural artefacts, such as shared language and cultural tools. Socio-cultural conditions significantly impact the construction of knowledge and understanding (Cobb, 1994; Cobb \& Yackel, 1996). This perspective provides a viable way for 
understanding, describing, and interpreting the 48 participating pre-service and in-service teachers' experiences of mathematics learning and teaching in this study.

\section{The Research Method}

Based on the socio-cultural perspective, the study designs its research method as a qualitative approach. The utilization of the qualitative approach is suitable for understanding, describing, and interpreting the participating teachers' experiences of online mathematics teaching. Denzin and Lincoln (2011) argue that qualitative researchers "study things in their natural settings, attempting to make sense of or interpret phenomena in terms of the meanings people bring to them." (p. 3). The quality interaction between the researchers and the participants would generate valuable information relative to the understanding and the interpretation of the research findings.

Creswell (2013) contends that qualitative researchers are connected to their theoretical perspectives to the research problems, in order to address the meaning that individuals or groups ascribe to a social or human activity. Smith et al. (2009) argued that IPA is an interpretive research approach in qualitative studies, with the emphasis on capturing "the 'lived experiences' of people, who have experienced similar (common) phenomena." (p. 4).

\section{The Data Collection and the Analytical Method}

The data collection and the data analysis for this research continued for one semester (the Fall semester of 2020). The data sources include zoom observations, pre-service and in-service teachers' verbal and written responses to reading reflections, participants' reactions to the films' assignments, reflections on the course activities, such as non-routine problem solving and lesson-plan critiques, presentations, and a final reflective paper. The instructor of the course and the primary researcher, acted as the participant-observers, a facilitator, and a coach in the classroom. The co-researcher was the classroom teaching assistant, who is a third-year doctoral student in the research institute. The on-going process of sharing understandings and interpretations of the findings between the researchers and the participants (i.e., triangulation of data processing) plays an important role for the establishment of a caring community and for one of trust.

Triangulation occurs in three ways. First, we triangulate the data via an ongoing conversation with the participants via email, Blackboard, Zoom meetings, and phone throughout the semester. Second, we triangulate the data by comparing multiple data sources (i.e., reading reflections, zoom discussions, email, blackboard, and phone conversations). Third, we triangulate the data through member checking (i.e., the exchange of ideas between the researchers). The data collection occurs throughout the course of a semester.

The data analysis consists of coding, which includes descriptive, summative, and holistic codes. Descriptive codes are the key words, which capture the participants' concrete reactions in a particular context. Summative codes are the codes, which represent the main ideas from the participants toward a specific 
research area. Descriptive and summative codes are integrated, synthesized, and then evolved into holistic codes, which provide the emerging patterns. The codes are generated by using NVIVO. NVIVO is a qualitative data analytical computer software package produced by QSR International; and it helps qualitative researchers to organize, analyze and find insights in unstructured or qualitative data, such as interviews, open-ended survey responses, journal articles, social media, and web content, where deep levels of analysis on small or large volumes of data are required (McNiff, 2016).

Based on the emergent patterns, the categories of themes are identified, such as the beliefs and problems related to online mathematics teaching, learning, and assessment, realizations, and possibilities.

\section{A Search for Meaning}

Throughout the semester, the primary researcher engaged the participating preservice and in-service teachers via online teaching and learning activities. These activities included the discussions and reflections on reading assignments, as well as non-routine problem-solving activities by using a variety of virtual tools for mathematical modeling and representations. In addition, the primary researcher incorporated small-group interactions and collaborations via Blackboard for sharing ideas and information, thereby creating a learning community by developing and sharing lesson plans and providing peer critiques, and teaching presentations.

In what follows, we present four samples of the participating pre-service and inservice teachers' reflections on their online lesson plans and teaching strategies. The first sample is presented by a female special education pre-service teacher developing her first online lesson plan.

The critiques from my colleagues helped me to improve my lesson plan; and fill in the missing gaps. My assessment originally lacked depth. My colleagues all suggested in one way or another to add to both my formative and summative assessments. One of my colleagues gave me good advice. He said, 'Always start with the end of your lesson in mind, this will help you develop a strong and explicit lesson that anyone could come in and teach if needed.' Peer's name). I do treasure the wise words of my fellow classmates who were gracious in giving both accolades and constructive criticism (Special Education Pre-service Teacher's Reflection on Online Lesson Plan).

The second sample is presented by a female early-childhood in-service teacher, developing an online-lesson plan for the first time.

"Preparing this lesson plan was an arduous and confusing endeavor. This was particularly true for me, as I do not have to generate this type of lesson plan [online] with the type of students I teach; nor do I have extensive experience writing lesson plans for online teaching in general. My classmates assisted me immensely in their constructive criticism. (In-service Early-Childhood Teacher's Reflection on Online-Lesson Plan)

The third sample lesson plan reflection is presented by a special education inservice teacher. He starts by saying that he designs his lesson from a diagnostic perspective, small group instruction, manipulatives, and technology. 
"The feedback I received from my peers, such as virtual manipulatives and circle manipulatives were very helpful for modification of my lesson plan. I also received feedback about a brain-break. Generally, lessons are 45 to 60 minutes; a brainbreak for third graders is necessary." (Special Education In-service Teacher's Reflection on Online Lesson Plan)

The fourth lesson plan reflection is presented by a female pre-service earlychildhood teacher. As a beginning teacher, she appreciates the challenges of stepping into a new and unfamiliar territory. In addition, she values the collaboration with her colleagues and peer critiques' aspect of the lesson plan processes.

"At first, I was nervous. I did not have any prior experience about writing online lesson plans and teaching them. I think that we teachers should shift away from the traditional style of teaching, where students are passive recipients. I appreciate the feedback given to me by my colleagues; and I used these to adjust my lesson." (Pre-service Early-Childhood Teacher's Reflection on Online Lesson Plan)

The participating pre-service and in-service teachers discuss their beliefs regarding online mathematics teaching, learning, and assessment in terms of their realizations, concerns, struggles, and limitations related to their online mathematic instructions. The participants agree the benefits of online mathematics teaching and learning; and they acknowledged their problems. We use a categorized themes table to summarize the participants' beliefs of the benefits and problems, as regards teaching mathematics online.

Table 1: Categorized Themes of the Beliefs and Problems Regarding Online Mathematics Teaching and Learning

\begin{tabular}{|c|c|c|}
\hline Categories & Benefits & Problems \\
\hline Resources & $\begin{array}{l}\text { range of multi-modality } \\
\text { resources }\end{array}$ & $\begin{array}{l}\text { lack of internet, devices, } \\
\text { technology, and family support }\end{array}$ \\
\hline Applicability & $\begin{array}{l}\text { convenience, flexibility, and } \\
\text { accessibility, differentiated, } \\
\text { Individualized and special } \\
\text { education }\end{array}$ & $\begin{array}{l}\text { hard to implement in special } \\
\text { education }\end{array}$ \\
\hline Capability & $\begin{array}{l}\text { creativity, innovation, } \\
\text { technology, and independent } \\
\text { learning, }\end{array}$ & $\begin{array}{l}\text { lack of training including } \\
\text { knowledge, skills, and } \\
\text { confidence in online teaching }\end{array}$ \\
\hline Assessment & $\begin{array}{l}\text { a variety of forms, efficient, fast, } \\
\text { reviewable }\end{array}$ & $\begin{array}{l}\text { issues in integrity, authenticity } \\
\text { and struggles in assessment }\end{array}$ \\
\hline Relationship & $\begin{array}{l}\text { connection, interaction, } \\
\text { collaboration, communication, } \\
\text { and socialization }\end{array}$ & $\begin{array}{l}\text { lack intimate participation, } \\
\text { connection, interaction, } \\
\text { communication, and } \\
\text { socialization }\end{array}$ \\
\hline Environment & $\begin{array}{l}\text { learning environment } \\
\text { management, participation, } \\
\text { involvement, and distraction }\end{array}$ & $\begin{array}{l}\text { out of control in learning } \\
\text { environment management } \\
\text { including participation, } \\
\text { involvement, and distraction }\end{array}$ \\
\hline
\end{tabular}

\section{Benefits: Range of Multi-Modality Resources}

The multi-modality aspect of available educational resources is recognized by participants as the number-one benefit of online mathematics teaching. Almost all 
the participants $(45 / 48)$ said that the internet provides a vast number of resources, like websites, tools, and media that support online mathematics education. For example, one participant said, "online teaching allows the teacher to take advantage of a ton of digital-learning tools, platforms, and online resources." Another teacher stated, "there is a wide range of educational materials available in an online classroom - for both the students and the teachers to enjoy."

The participants not only acclaimed the extensive resources for onlinemathematics instruction; but they also reflected that the application of multimodality resources provides self-exploration opportunities for both teachers and students. They stated that using multi-modality resources online helps students to become engaged and motivated to understand mathematical concepts and to build up one's mathematical skills.

One teacher narrated: "teachers can utilize helpful online software. This could include relying on and using different digital learning tools for students to use, in order to help them to improve their mathematical skills and understanding." Another teacher expressed a similar idea, that "online learning is an engagement that offers kids with all of the moving parts and vibrant colors of mathematical instruction, which really helps to motivate and engage the students."

\section{Benefits: Convenience, Flexibility, Accessibility, Comfort, Less Distraction}

The second benefit reflected by participants regarding mathematics teaching and learning online is the convenience, flexibility, and accessibility of being able to teach anywhere, at any time, and when using any format. One teacher said, "students are not necessarily constrained to the lessons at any given time of the day; they can access the course content whenever it is convenient for them, by day or by night."

Another teacher claimed, "one of the many benefits to online teaching is the flexibility of the schedule with the online school. You can schedule assignments and have students do assignments at their own pace and in their own time." A third teacher reported, "a benefit to online teaching and learning mathematics is the flexibility of the online schedule. An online schedule allows students to work at their own pace, and in their own time. Students can log on when they want, and take as much time as they need to complete an assignment."

The participating pre-service and in-service teachers argued that online learners can learn at their own pace and from the comfort of their own homes, which prevents social distraction, like behaving inappropriately, making a noise, or participating in classroom gossip.

\section{Benefits: Creativity, Innovation, Technology, and Independent Learning}

The third major benefit of teaching mathematics online lies in the advantages of creativity, innovation, technology, and independent learning. One of the participating teachers explained how online learning fosters creativity: "the internet provides a nearly endless supply of resources and ideas with regard to mathematics. You can easily find interactive teaching aids, videos, games, and so forth, for use during just about any lesson you could want to teach." 
Another benefit of online teaching is that there are so many technological innovations that allow an educator to integrate face-to-face classroom practices into an online learning environment. To explain this advantage, one teacher said, "online education can help students to develop their technological skills; since students are learning to use different forms of technology, like computers and tablets, to complete assignments and assessments, and to compute mathematical equations." The participants also reported that online mathematics learning cultivates students' independent learning ability.

\section{Benefits: Interaction, Connection, Collaboration, and Involvement}

The participants stressed that online teaching provides creative ways to facilitate lessons, collaboration, and learning. Students are more engaged through different technological tools, such as interactive games, forums, email, Zoom, and Google Classroom. Each platform allows students and teachers to interact and enhance their collaboration, because "students can collaborate with their peers, as well as with their teachers, which complements the needs of the students;" and "it enhances teachers' and students' virtual communication and collaboration skills."

The nature of online teaching and learning has the benefit of helping students feel more connected with each other in the absence of a classroom, and with others nationwide and globally, which provides learning experiences in a global way. One teacher mentioned, "a virtual classroom can be utilized anywhere around the world, so students could possibly be working and interacting with peers from other countries or states." The participants also emphasized that online learning helps to create a relationship between a teacher and the students; and it allows teachers to know their students better.

\section{Benefits: Differentiation, Individualization, and Special Education}

The fifth benefit of teaching mathematics online comes from the aspects of differentiation, individualization, and special education. The participating teachers argue that online learning provides teachers with more opportunities for tailored instruction and individualized instruction, especially for struggling students and special education students in the general education classroom settings. One teacher says "online teaching and learning opens up opportunities for both students and educators with special needs. Disabilities can restrict both educators and students from attending school. By being allowed to attend school in their homes, disabled individuals on both sides of the educational spectrum would be able to be part of the educational experience."

The Internet gives teachers the opportunity to take into consideration the needs of this new generation that is so tuned into technology, and which prefers receiving information quickly from the multiple sources of the media.

\section{Problems: Knowledge, Skills, and Confidence}

Some participants resist teaching mathematics online (16 out of 48 participants), although they agree with its benefits. Objections include a lack of time, 
knowledge, skills, and confidence in teaching mathematics online, lack of effective dynamic interaction and communication online, lack of internet access, lack of technological support in poor communities, feeling out-of-control of the learning environment and distraction, as well as issues related to the authenticity of the assessment, and the needs of special-education students.

The participating teachers mentioned their level of knowledge, skills, and confidence relative to adequately presenting the material in a virtual setting. One teacher reported, "I had difficulty with teaching skills online, especially since there was a lack of knowledge to deal with issues like limited attention span, lack of attentiveness. It seemed as if there were too many things online, it's overwhelming." Another teacher echoed, "Many teachers who are in the workforce do not have high-tech skills; and they struggle to manage the computer. How to use a digital tool, how to access different software, and to make it learnable, how to deal with poor internet connections, or with the unaffordable internet costs, in order to sustain the long hours of online-learning connections."

The lack of technological skills often leads to reducing teachers' confidence in online-mathematics teaching. "The issue would be my confidence to teach a complex lesson, without being able to fully explain or gauge my students."

\section{Problems: Participation, Connection, Interaction, Communication, and Socialization}

There are widespread concerns about the lack of interpersonal relationships, when teaching mathematics online, including the lack of participation, connection, interaction, communication, and intimacy. Other issues mentioned by the participants are relative to social and emotional concerns, such as not being able to get the same interactions with students online. One teacher pointed out that "one of the things I have observed over this past semester is that students have a very difficult time interacting with one another. I feel as though a plethora of students' social skills have regressed over the period that we have been attending school in the virtual format."

The participating teachers mentioned the limitations of online learning relative to social and emotional development. They argued that it is difficult for children to play, and to interact with each other.

\section{Problems: Internet Access, Equity, and Family Support}

The participating teachers stated the lack of necessary resources, such as the internet, devices, and technology as the third major problem with teaching mathematics online. One of the participating teachers said, "one of the biggest obstacles regarding online teaching and learning is the fact that not all students would have access to the computers or to the internet, when necessary." Another teacher said, "One obstacle and limitation relative to online teaching and learning mathematics is the home situations and the home life. There are times that students do not have very good Wi-Fi at their homes; and many schools do not supply laptops or iPads." 
Some students were unable to navigate the internet without the help of an adult. This leaves students to rely on their parents' schedules to help them complete their schoolwork. Some students also have poor internet connections. Poor internet connection can make it difficult for students to log on, to hear directions, and to participate in conversations. Accessibility and technical issues are two concerns that go hand-in-hand. One teacher said, "if students do have internet at their house, they might not have computer accessibility, or they might be sharing a computer with a number of other relatives in their home. This could be hard for students to have time to complete the work they need to. It could also be a scheduling issue."

As one teacher observed, "online teaching mathematics requires the support of family or caregivers. Many younger students are going to need assistance with technology, in order to study online." The dilemma is that, on the one hand, younger children may struggle when using the keyboard, while on the other hand, many parents have full-time jobs, so that they cannot afford to stay at home. They may also not have the money to pay for a helper to assist their child during the school day, which could cause personal issues. This issue was best expressed by one teacher, "one of my biggest struggles with online teaching and learning in mathematics is the students relying on their technological support, while nobody is nearby for help, so that they simply get stuck and cannot figure out a problem."

\section{Problems: Integrity and Authenticity in Assessment}

Many participating teachers show concerns about integrity and authenticity regarding online assessment. The most frequent words reflected from participants are "challenging", "hard", "difficult", "inefficient", and "less integrity". One teacher stated, "I believe that assessing students' learning online is extremely difficult." Another teacher expressed the same concern, "assessments are less authentic. I do not believe that online assessments can accurately tell a student's full independent knowledge. I am concerned about inefficiency and maintaining academic integrity."

From analyzing teachers' responses, we found several reasons for the above concerns. First, generating an authentic assessment for all students from a variety of locations is difficult; because the teacher cannot fully monitor the learner's environment. Second, teachers face the outside sources that they do not have control over, such as students searching for answers online, getting help from family members or parents. As a result, it is a huge challenge for many participating teachers to truly assess the students and to get a gauge on what they know.

\section{Realizations Relative to Online Instruction}

The participating pre-service and in-service teachers discuss their realizations regarding the curriculum, technology, pedagogy, and culture. Many teachers realize the pros and cons of lesson planning, material choosing, and implementing. One teacher responded, "one of the things that influenced my growth in this area is logging into my zoom classes and being excited to teach every lesson. Students respond more effectively and tend to participate more when their teacher is positive and excited about what they are teaching." 
Although shifting teaching to the online format causes a plethora of technological challenges for teachers, many teachers reported the necessity of incorporating technology in online mathematics teaching. In addition, the participating teachers reflected on the socio-cultural aspect of online teaching and learning. One teacher said, "one of the major realizations I had this semester was learning the concept of ethno-mathematics, which focuses on the integration of history, culture, and mathematics. Mathematics is interconnected with history, culture, and social activities. Mathematics relates to people's culture, and it should be relevant to specific cultures.

This is an important aspect of teaching." The participating teachers reflected on their realizations throughout the semester, such as access and equity in online teaching and learning, culturally responsive online pedagogy, and mathematical connections to students' experiences.

\section{The possibilities of Online Mathematics Teaching and Learning}

The participating teachers provided many insights about how to engage students in online mathematics learning. One teacher said, "it is important for teachers to incorporate four key skills (the $4 \mathrm{C}^{\prime} \mathrm{s}$ ) in the online mathematics curriculum, in order to prepare the students for effectively connecting with a global society: critical thinking, communication, collaboration, and creativity." In addition, they argued that to plan a meaningful lesson, teachers must be knowledgeable about the content they are teaching. Many participants mentioned the critical role of creativity in online teaching. Another important factor of successful online teaching that was expressed by the participants was flexibility and adaptability during this time of uncertainty.

The participating teachers stated that online teaching and learning ought to be a student-centered approach, where content and learning experiences are connected. To achieve this goal, they suggested hands-on and experimental activities throughout a variety of engaging apps and activities. Incorporating technology into mathematics instruction leads to inclusion. The participants discussed the crucial role of technology, such as Zoom, Google docs, forums, online apps, and games. Online teacher-student and student-student relationships also play an important role in students' social and emotional development and successful learning. This connection is stressed by many participating teachers. Establishing a good relationship between teachers and parents was also highlighted by the participants. To this point, one teacher said, "Closely working with parents and families and creating positive relationships with them would be helpful when teaching online."

The participants asserted that while maintaining a supportive environment, teachers should also be aware of the importance of communication, interaction, reflections, and adaptability for online teaching and learning. 


\section{Discussions}

The findings of this study suggest that a range of factors impact the participating teachers' beliefs and perspectives towards online mathematics teaching and learning during the time of the COVID-19 pandemic. These factors include interactions, communication, and peer support. In addition, the findings of the study show that a few social and cultural factors impact online mathematics teaching and learning, such as knowing and understanding students' social and cultural background, technological access and equity in mathematics education, learners' social and emotional development, as well as parents' involvement. The results of the study support similar findings by other scholars, thereby demonstrating the challenges that mathematics teachers face regarding online teaching and learning during the pandemic (Wachira \& Keengwe, 2010; Engelbrecht \& Harding, 2005).

In addition, the study's findings echoed the call for better collaboration among pre-service and in-service mathematics teachers through a mentoring model, in order to facilitate mathematics teachers' professional development (Gueudet et al., 2012).

Engaging the participating pre-service and in-service teachers in online mathematics teaching and learning must be understood within the socio-cultural context in which they live and interact. Most of the participating teachers had little knowledge, skills, and experiences regarding online mathematics teaching prior to the COVID-19 pandemic. The findings of the study suggest that about 33\% of the participating teachers were not comfortable in online mathematics teaching.

One possible explanation for this is their uncertainty regarding how to incorporate technology in their day-to-day mathematics teaching and their lack of knowledge and skills for online teaching.

Although almost $67 \%$ of the participating pre-service and in-service teachers were supportive of online teaching and learning, we argue that ultimately, it is the actions of the participants that define their interests, beliefs, and practices. Transformation from traditional teaching to online instruction requires a change in perspectives. In addition, it requires adequate resources, technological support, and onsite professional development opportunities.

\section{Concluding Remarks}

Teaching mathematics online is challenging; but exploring the mechanism of engaging pre-service and in-service teachers in online mathematics instruction is rewarding. Our findings indicated that the teaching transformation from inperson, to online teaching requires the enhancement of pre-service and in-service teachers' competencies with online teaching, including technological support, pedagogical updates, communication skills, and classroom management strategies within a virtual setting. The findings of the research also suggest that strengthening pre-service and in-service teachers' collaboration and mentorship requires a pragmatic solution for addressing these needs. 
Our findings offer mathematics teachers insights and the means for proceeding in online mathematics instruction. Below, we provide some suggestions and approaches for successful online-teaching methods. In our study, we used course materials that are manageable, meaningful, and contextual, such as Electronic Reserved articles and Films on Demand, for reading, observing, and critically reflecting; Blackboard interactions and discussions; Zoom meetings for wholeclass discussions; and non-routine problems for mathematical modeling, representation, and communication.

Teachers and teacher-educators can utilize a variety of strategies and methods for meaningful mathematical engagement, including zoom meetings, small-group meetings, one-on-one interactions, Blackboard discussions, and project-based teaching presentations. The key is to be found in making teaching simple and feasible.

Contextualizing online mathematics teaching and learning methods geared towards the participating pre-service and in-service teachers' needs, is pivotal for active engagement. Establishing social norms for online teaching and learning with clear communication of expectations is a necessary component for successful online instruction.

In addition, transparency through open conversation and creating a safe and riskfree climate are crucial for online learning. Active listening, meeting students where they are, keeping the teaching and learning manageable and meaningful, valuing students' voices, one-on-one interactions, small-group cooperative learning, collaborating with colleagues, project-based activities, and critical reflections are important factors for successful online teaching and learning.

\begin{abstract}
About the Authors:
Roland G. Pourdavood is a professor of mathematics education at Cleveland State University, Department of Teacher Education. His research interests include mathematics teachers' dialogue and reflection for transformation and school reform. In addition, he focuses on cultural diversity, the socio-cultural aspects of education, and emancipatory action research for personal and social praxis.
\end{abstract}

Xuan Song is a third-year doctoral student of learning and development in urban education at Cleveland State University. His current research interests include curriculum development and instruction, teacher immediacy and teacher-student relationships, motivation, parenting style and students' well-being. He is also interested in second-language acquisition, bilingualism, and the relationship between language and thinking.

\title{
11. References
}

Adedoyin, O. B., \& Soykan, E. (2020). COVID-19 pandemic and online learning: The challenges and opportunities. Interactive Learning Environments, 1-13. https:// doi.org/10.1080/10494820.2020.1813180

Adnan, M., \& Anwar, K. (2020). Online learning amid the COVID-19 pandemic: Students' perspectives. Journal of Pedagogical Sociology and Psychology, 2(1), 45-51. http:/ / www.doi.org/10.33902/JPSP.2020261309 
Akdemir, O. (2010). Teaching math online: Current practices in Turkey. Journal of Educational Technology Systems, 39(1), 47-64.

Bullock, D., (2004). Moving from theory to practice; An examination of the factors that preservice teachers encounter in the attempt to gain experience in teaching with technology during field-placement experiences. Journal of Technology and Teacher Education, 12(2), 211-237.

Cobb, P. (1994). Where is mind? Constructivist and socio-cultural perspectives on mathematical development. Educational Researcher, 23(7), 13-20. https:// doi.org/10.2307/1176934

Cobb, P., \& Yachel, E. (1996). Constructivist, emergent, and socio-cultural perspectives in the context of developmental research. Educational Psychologist, 31(3/4), 175-190. https://doi.org/10.1080/00461520.1996.9653265

Creswell, J. W. (2013). Qualitative inquiry and research design: Choosing among five approaches ( $3^{\text {rd }}$ ed.). Sage Publications, Inc.

Denzin, N. K., \& Lincoln, Y. S. (2011). The SAGE handbook of qualitative research (4th ed.). SAGE.

Engelbrecht, J., \& Harding, A. (2005). Teaching undergraduate mathematics on the internet. Educational Studies in Mathematics, 58(2), 235-252.

Fauzi, I., \& Khusuma, I. H. (2020). Teachers' elementary school in online learning of COVID-19 pandemic conditions. Journal Iqra': Kajian Ilmu Pendidikan, 5(1), 58-70. https://doi.org/10.25217/ji.v5i1

Green, M., \& Piel, J. A. (2010). Theories of human development: A comparative approach. Pearson Education.

Guba, E. G., \& Lincoln, Y. S. (1994). Comparing paradigms in qualitative research. In Denzin, N. K. \& Lincoln, Y. S. (eds.), Handbook of Qualitative Research (pp. 105-117). Thousand Oaks, CA: Sage.

Guba, E. G., \& Lincoln, Y. S. (1989). Fourth generation evaluation. Sage.

Gueudet, G., Scaristan, A. I., Lavergne, S. S., \& Trouche, L. (2012). Online paths in mathematics teacher training: New resources and new skills for teacher educators. ZDM Mathematics Education, 44, 717-731. https://doi.org/10.1007/s11858-0120424-z.

Herzig, A. (2020). Surprise: Transitioning to online teaching. AMS Director of Education. https://blogs.ams.org/matheducation/2020/03/16/2937/

Kay, R. H. (2006). Evaluating strategies used to incorporate technology in pre-service education: A review of the literature. Journal of Research on Technology in Education, 38(4), 383-408.

Koehler, M., \& Mishra, P. (2009). What is technological pedagogical content knowledge (TPACK)? Contemporary Issues in Technology and Teacher Education, 9(1), 60-70.

McNiff, K. (2016). What is qualitative research? The NVivo Blog. QSR International. https://www.qsrinternational.com/nvivo-qualitative-data-analysissoftware/resources/blog/what-is-qualitative-research

Moreno-Guerrero, A. J., Aznar-Díaz, I., Cáceres-Reche, P., \& Alonso-García, S. (2020). Elearning in the teaching of mathematics: An educational experience in adult high school. Mathematics, 8(5), 840.

Radford, L., Miranda, I., \& Lacroix, G. (2018). On teaching and learning mathematics from a cultural-historical perspective. In Teaching and Learning Secondary School Mathematics (pp. 27-38). Springer, Cham. https://doi.org/10.1007/978-3-31992390-1_4

Rapanta, C., Botturi, L., Goodyear, P., Guárdia, L., \& Koole, M. (2020). Online university teaching during and after the COVID-19 crisis: Refocusing teacher presence and 
learning activity. Post Digital Science and Education, 923-945. https://doi.org/10.1007/s42438-020-00155

Roth, W. M., \& Walshaw, M. (2015). Rethinking affect in education from a societalhistorical perspective: The case of mathematics anxiety. Mind, Culture, and Activity, 22(3), 217-232. https://doi.org/10.1080/10749039.2015.1016239

Rowlands, S. (2010). A pilot study of a cultural-historical approach to teaching geometry. Science \& Education, 19(1), 55-73. https://doi.org/10.1007/s11191-008-9181-3

Selden, A., \& Selden, J. (1997). Should mathematicians and mathematics educators be listening to cognitive psychologists? M.A.A Research Sampler 2. http://www.maa.org/t_and_l/sampler/rs_2.html

Smith, J.A., Flowers, P., \& Larkin, M. (2009). Interpretative Phenomenological Analysis: Theory Method and Research. London: Sage.

Vygotsky, L. S. (1978). Mind in society: The development of higher psychological processes. Cambridge: Harvard University Press.

Wachira, P., \& Keengwe, J. (2011). Technology Integration Barriers: Urban School Mathematics Teachers' Perspectives. Sci Educ Technol, 20, 17-25. https://doi.org/10.1007/s10956-010-9230-y 